\title{
Growth factors in pulmonary arterial hypertension: Focus on preserving right ventricular function
}

\author{
G. CSÓSZA, K. KARLÓCAI, G. LOSONCZY, V. MÜLLER and Z. LÁZÁR*
}

Department of Pulmonology, Semmelweis University, Budapest, Hungary

Received: October 13, 2019 • Accepted: February 17, 2020

Published online: July 17, 2020

(c) 2020 The Author(s)

\begin{abstract}
Pulmonary arterial hypertension $(\mathrm{PAH})$ is a rare and progressive disease, characterized by increased vascular resistance leading to right ventricle $(\mathrm{RV})$ failure. The extent of right ventricular dysfunction crucially influences disease prognosis; however, currently no therapies have specific cardioprotective effects. Besides discussing the pathophysiology of right ventricular adaptation in PAH, this review focuses on the roles of growth factors (GFs) in disease pathomechanism. We also summarize the involvement of GFs in the preservation of cardiomyocyte function, to evaluate their potential as cardioprotective biomarkers and novel therapeutic targets in PAH.
\end{abstract}

\section{KEYWORDS}

pulmonary hypertension, heart failure, cardiac remodeling, predictive marker, cardioprotection, growth hormones

\section{INTRODUCTION}

Pulmonary hypertension (PH) is a progressive disease characterized by an increased mean pulmonary arterial pressure (mPAP $\geq 25 \mathrm{mmHg}$ ) [1]. Classes of $\mathrm{PH}$ are defined and regularly updated by the WHO based on hemodynamic and clinical characteristics (Table 1). According to the hemodynamic definition pre-capillary and post-capillary $\mathrm{PH}$ can be distinguished by a

* Corresponding author. Department of Pulmonology, Semmelweis University, 25-29 Tömő Str., 1083 Budapest, Hungary. Tel.: +36 1355 9733; fax: +36 1214 2498, E-mail: lazar.zsofia@med.semmelweis-univ.hu 
Table 1. Classification of pulmonary hypertension

\begin{tabular}{lcc}
\hline \multirow{2}{*}{$\begin{array}{l}\text { Hemodynamic } \\
\text { classification }\end{array}$} & \multicolumn{2}{c}{ Pulmonary hypertension mPAP $>25 \mathrm{mmHg}$} \\
\cline { 2 - 3 } Clinical classification & Pre-capillary PH, PAWP $<15$ & $\begin{array}{c}\text { Post-capillary PH, PAWP }>15 \\
\text { mmHg }\end{array}$ \\
\hline & WHO Group 1. Pulmonary arterial & hypertension \\
WHO Group 3. PH due to lung & WHO Group 2. PH due to left heart \\
disease and/or hypoxia & \\
WHO Group 4. Chronic & \\
thromboembolic PH or other & \\
pulmonary artery obstructions & \\
WHO Group 5. PH with unclear & \\
and/or multifactorial mechanisms & \\
\hline
\end{tabular}

mPAP: mean pulmonary arterial pressure; PH: pulmonary hypertension; PAWP: pulmonary arterial wedge pressure.

normal and elevated pulmonary arterial wedge pressure (PAWP), respectively. The predominant pathophysiological abnormality in pre-capillary $\mathrm{PH}$ is the remodeling of the arterial wall, particularly in pulmonary arterial hypertension (PAH, WHO group 1). The increased proliferation and inhibited apoptosis of lung vascular endothelial cells, pulmonary arterial smooth muscle cells (PASMC) and fibroblasts result in remodeling of the muscular type of pulmonary arteries, manifested as intimal hyperplasia, medial thickness, plexiform lesions and in situ thrombosis [1]. In addition, other mechanisms as hypoxic vasoconstriction (WHO group 3) and mechanical obstruction by thrombi (WHO group 4) also play a role in the increase in pulmonary vascular resistance (PVR). In post-capillary $\mathrm{PH}$ the underlying disorder is a left heart disease and the consequent pulmonary congestion causes a rise in PAWP (WHO group 2). In combined pre-capillary and post-capillary $\mathrm{PH}$ in addition to the presence of increased left ventricle (LV) pressure and PAWP, pulmonary arterial remodeling is pronounced and leads to an increase in PVR. Irrespective of the etiology of PH right ventricle (RV) pressure overload leads to right ventricular myocardial hypertrophy, dilatation and right ventricular failure at advanced stages. The mechanism of RV adaptation involves complex processes, which are influenced by different factors including the etiology of PAH, genetic predispositions, neurohumoral regulation, immune and inflammatory activation [2].

Growth factors (GFs) are diffusible signaling proteins that stimulate cell growth, cellular differentiation and survival, tissue inflammation and tissue repair. Several studies described the involvement of GFs in the development of PAH [3-6]. Moreover, accumulating evidence suggests that they may also contribute to the preservation of right heart function, but also influence the development of RV remodeling and disease progression (Fig. 1). Notably, some of these mediators also have well-known effects during myocardial protection in cardiac disorders such as ischemic heart disease, myocardial hypertrophy or left heart failure [3, 4]. GFs may, in addition, support better myocardial adaptation in response to pressure overload of the RV and may be related to better prognosis in PAH. In the current review, we aim to systematically discuss the evidence on the involvement of the major GFs in the pathophysiology of PAH and the consequent right heart failure and evaluate their potential as cardioprotective biomarkers. 


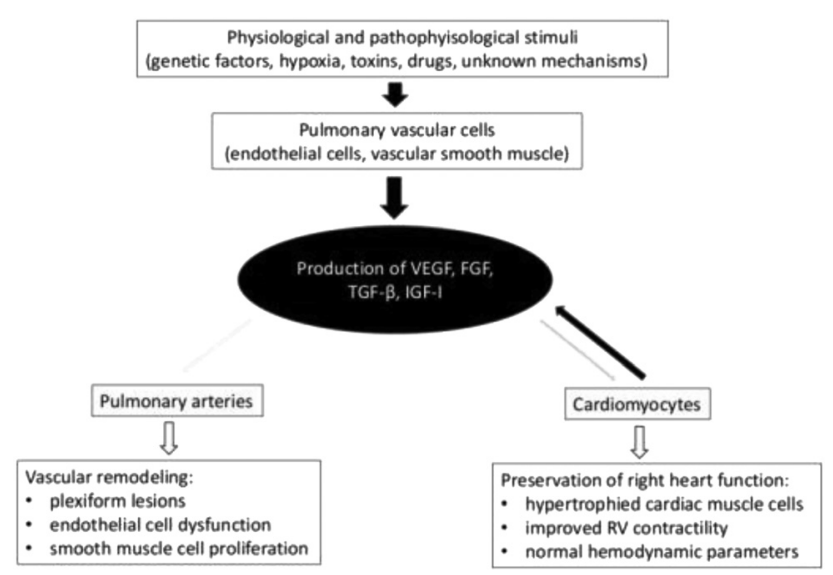

Fig. 1. The roles of growth factors in the pathophysiology of PAH. Growth factors are produced in pulmonary vascular cells and cardiomyocytes in response to various stimuli in PAH. These factors play a role both in the development of pulmonary vascular remodeling and the modulation of right ventricular function. FGF: fibroblast growth factor, IGF-I: Insulin-like growth factor-I; PAH: pulmonary arterial hypertension; RV: right ventricle; TGF- $\beta$ :transforming growth factor- $\beta$; VEGF: vascular endothelial growth factor

\section{THE REGULATION OF GROWTH FACTORS (GFS) DURING THE DEVELOPMENT OF PAH}

GFs regulate various cellular functions such as survival, proliferation, migration and differentiation and thus play significant roles in the repair mechanisms of organs under physiological circumstances [3].

In PAH GFs affect the development of vascular remodeling, the proliferation of endothelial cells, smooth muscle cells and fibroblasts, and the formation of the plexiform lesions $[5,6]$. Several GFs are expressed locally in the pulmonary parenchyma and in the plexiform lesions. The expression of platelet-derived growth factor (PDGF) and PDGF receptor was elevated in explanted lungs of patients with severe $\mathrm{PAH}$ [6], and the appearance of vascular endothelial growth factor (VEGF) and VEGF receptors is confirmed in the plexiform lesions and medial smooth muscle cells of the proximal arteries during lung autopsies [7]. Nerve growth factor (NGF) expression and its secretion were increased in the pulmonary arteries of patients with pre-capillary $\mathrm{PH}$ complicating chronic obstructive pulmonary disease (group 3 in Table 1) and in experimental PAH induced by monocrotaline administration or chronic hypoxia [8]. Other studies proved elevated circulating levels of these factors in patients, and found high transpulmonary gradients of these molecules suggesting their pulmonary production [9].

The mechanisms behind the abnormal expression of GFs in the lungs in PAH are only partially known, and multiple pathways have been implicated. In $80 \%$ of familiar PAH (FPAH) the mutations of the bone morphogenic protein receptor type 2 (BMPR2), a member of the transforming growth factor- $\beta$ (TGF- $\beta$ ) superfamily can be identified, and approximately $20 \%$ of sporadic idiopathic PAH (IPAH) patients carry this mutation. Epigenetic factors play a role in its penetrance [10]. BMPs can activate various receptors such as the BMP type I and type II and 
also the activin type II receptor, however only BMPRII is specific for BMPs. In the vasculature the signaling is mainly mediated by BMP2, 4, 6, 9, and 10, which can activate all three receptors and play a prominent role in vasculogenesis and angiogenesis. The disturbed BMP signaling via the intracellular specific intracellular signal transduction protein (SMAD) pathway contributes to the development of abnormal vascular remodeling in PAH [11].

A further $5 \%$ of FPAH patients have rare mutations in other genes of the TGF- $\beta$ superfamily including activin-like receptor kinase-1 or endoglin. These genetic disorders result in abnormal tissue repair and vascular remodeling caused by the abnormal growth response of pulmonary artery smooth muscle cells and the reduced apoptosis of endothelial cells [12]. Interestingly, in the animal model of Schistosoma infection, PAH is induced as a result of the pulmonary activation of TGF- $\beta$ by bone marrow-derived thombospondin-1 [13].

Hypoxia is a powerful stimulus for pulmonary vasoconstriction and pulmonary vascular remodeling. The expression of VEGF and FGF (fibroblast growth factor)-2 is increased in endothelial cells by hypoxia-induced signaling molecules $[14,15]$. Furthermore, the expression of the growth differentiation factor 11, a member of the BMP/TGF- $\beta$ superfamily, is induced in pulmonary artery endothelial cells under hypoxia, which plays a crucial role in the development of hypoxia-induced PAH in animal models [16].

Exogenic stimuli such as drugs and toxins have been shown to be involved in the development of PAH. The tyrosine kinase inhibitor (TKI) dasatinib is successfully used in the treatment of chronic myelogenous leukemia, but case reports found an increased prevalence of $\mathrm{PAH}$ in treated patients, where PAH was (at least partly) reversible in most cases after the cessation of therapy $[17,18]$. It is presumed that the modulation of PDGF signaling by TKIs is responsible for the development of PAH [19].

\section{THE ADAPTATION OF THE RIGHT VENTRICLE (RV) IN PAH}

The anatomy and function of the RV is partially distinct from the LV, which is also reflected in its different adaptation mechanisms in response to pathophysiological processes. The RV pumps the blood into the low vascular resistant pulmonary circulation, a process requiring less stroke work compared to that of the LV, but the stroke volume is similar [20]. Exercise results in a decrease in PVR to prevent a significant increase in pulmonary pressure. Consequently, under physiological circumstances, the RV wall contains less muscular tissue and its compliance is also greater than observed in the LV. Therefore, in contrast to the LV, the RV can undergo significantly higher volume changes under pathological conditions [21].

In $\mathrm{PAH}$, sustained pulmonary vasoconstriction and excessive pulmonary vascular remodeling cause elevated PVR which is resistant to physical exercise. Due to the gradually increasing PVR, the RV produces higher systolic pressures to maintain blood flow. The constantly elevated $\mathrm{RV}$ and pulmonary pressures result in right ventricular remodeling. In early disease stages, concentric myocardial hypertrophy of the right ventricular wall is observed (adaptive remodeling), which is the result of upregulated intracellular protein synthesis and the increased size of cardiomyocytes; therefore, ventricular contractility and the systolic function also improve. As a consequence, hemodynamic parameters such as cardiac index and right atrial pressure remain normal [22]. 
As the disease progresses, the gradually increasing pressure overload induces eccentric myocardial hypertrophy mainly in the free wall of the RV, which is associated with increased collagen production but also with excessive degradation of normal extracellular matrix in the myocardium (maladaptive remodeling). The maladaptive hypertrophy and the additional volume overload due to increasing functional tricuspid regurgitation lead to progressive dilatation of the RV, deterioration of contractility and the systolic function [23]. This mechanism results in progressive RV dysfunction and failure at advanced disease stages as summarized in Fig. 2.

The prognosis of $\mathrm{PAH}$ is strongly associated with the grade of structural abnormalities of the RV [24]. More specifically, the increased right ventricular diameter is a biomarker of a poor prognosis; however, the increased wall thickness is related to reduced risk of mortality in patients with dilated RV [25]. In line with this, increasing evidence suggests that the detailed assessment of RV structure and function holds relevant prognostic information and can support treatment decisions to improve clinical outcomes [26].

The molecular mechanisms of RV myocardial adaptation are not yet completely understood. In PAH the pressure overload induces wall stretch, being the main trigger to initiate myocardial adaptation, which improves RV systolic function during early stages. Subsequently, in further phases of $\mathrm{PAH}$ ischemia and oxidative stress in the myocardium activate neurohumoral, inflammatory and immune processes, leading to extracellular matrix degradation and cardiomyocyte dysfunction and/or apoptosis [2]. These processes induce chamber dilatation and systolic dysfunction. The peculiarity of the right ventricular muscle is that when PVR is normalized (e.g. after pulmonary endarterectomy or lung transplantation), size, wall thickness and molecular differences normalize very rapidly through reversible remodeling [24].

As described above, GFs contribute to the development of vascular remodeling in $\mathrm{PAH}$, but some could also have a role in controlling myocardial adaptation to PAH. Myocardial ischemia, the imbalance between myocardial oxygen supply and oxygen demand, is caused by several mechanisms in PAH [27]. The disturbance of the alveolar gas exchange leads to chronic systemic hypoxemia. On the one hand, the increased right ventricular wall tension associated with

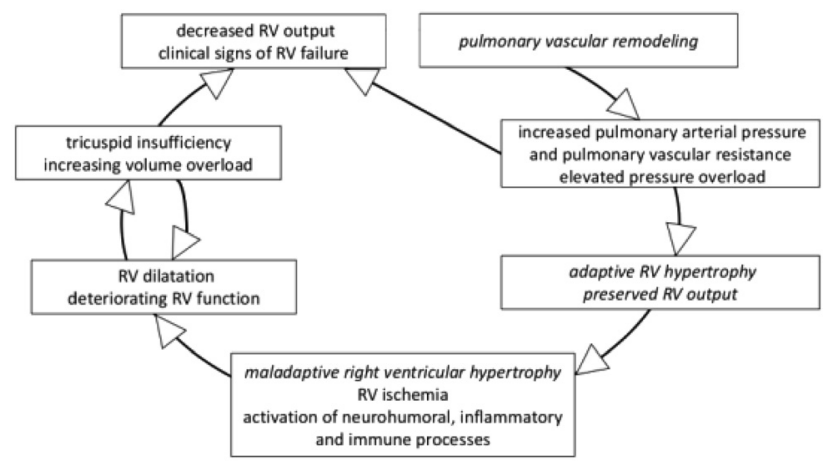

Fig. 2. The effects of increased pulmonary vascular resistance on the right ventricle in PAH. A schematic presentation of the vicious circle induced by increased pulmonary arterial vascular resistance on the morphology and function of the right ventricle in PAH. Mechanisms potentially influenced by growth factors are highlighted in italics. RV: right ventricle 
systemic hypotension impairs coronary perfusion. On the other hand, myocardial hypertrophy and the increased wall tension require increased oxygen supply. Several GFs are released by the myocardium during myocardial ischemia including the angiogenetic GFs such as VEGF, FGF and others which have direct myocardial protective effect such as IGF and TGF- $\beta[3,4]$.

In the following sections, we discuss GFs which potentially exert cardioprotective effects, contribute to right ventricular adaptation, as well as to hemodynamic changes in PAH. The known intracellular pathways of these factors are shown in Table 2 and Fig. 3.

\section{VASCULAR ENDOTHELIAL GROWTH FACTOR (VEGF)}

Members of the VEGF family including VEGF-A (called generally VEGF), -B, -C, -D, -E and the placental GFs play significant roles in angiogenesis [41]. VEGF-A is the most potent angiogenic factor, and it is produced in high amounts in the adult lung. The tyrosine kinase VEGF receptors are VEGFR-1 (Flt-1), VEGFR-2 (KDR/Flk-1) and VEGFR-3 (FLT-4). VEGFR-1 and VEGFR-2 are expressed in vascular endothelial cells, and upon activation they induce signals for proliferation, migration and remodeling.

VEGF was suggested to be involved in the formation of plexiform lesions, as this cytokine, produced by the modified smooth muscle cells of the plexiform lesions and the medial smooth muscle cells, can activate pulmonary endothelial cells expressing the VEGF receptor [42]. However, the overexpression of VEGF-A or VEGF-B in the lungs can partially restore endothelium-dependent function and ameliorate PAH in an animal model of chronic hypoxia [43, 44]. In support, VEGFR-2 blockade in combination with chronic hypoxia resulted in the development of severe PAH in an experimental model as the result of precapillary arterial occlusion induced by proliferating endothelial cells [45].

VEGF can be generated in the myocardium in response to myocardial ischemia [46]. VEGFR-1 and VEGFR-2 are expressed on both pulmonary vascular endothelial cells and cardiomyocytes, at least in rat models of $\mathrm{PH}$ [30], suggesting that VEGF stimulation can induce acute or chronic cardiac effects either by directly acting on cardiomyocytes or by exerting vascular effects. These receptors activate known cytoprotective pathways in myocytes such as the MEK1/2-Erk1/2-p90 rsk [3], which promotes cell survival by increasing the adhesive interactions between cardiomyocytes and extracellular matrix components [47]. In an animal model of hypoxia-induced $\mathrm{PH}$ the increased level of VEGF mRNA has been demonstrated in the myocardium, suggesting that VEGF may be one of the factors in the development of hypoxiainduced angiogenesis as shown by an increase in the number of capillaries per myocyte [30]. In support, VEGF mRNA expression was increased in rat RVs with adaptive hypertrophy compared to control animals, but it was unchanged in RV failure [37]. Moreover, the administration of VEGF to the recovery solution of the isolated rat heart can improve the functional recovery of the myocardium after ischemia-reperfusion injury [48].

An increase in circulating VEGF concentration was measured in patients with IPAH compared to controls $[49,50]$. In patients there was a significant positive relationship between plasma VEGF concentrations and the tricuspid annular plane systolic excursion, which is an echocardiographic marker of right ventricular systolic function [50]. In other words, patients with better right heart function had higher circulating VEGF values suggesting a possible role for this mediator in protection against the development of right ventricular failure. In line with this, 
Table 2. The intracellular signaling pathways of growth factors with putative cardioprotective effects

\begin{tabular}{|c|c|c|c|c|}
\hline Mediator & $\begin{array}{l}\text { Receptor } \\
\text { subtypes }\end{array}$ & Intracellular pathway & Effects & References \\
\hline \multirow[t]{4}{*}{ VEGF } & VEGFR1 & $\mathrm{MEK} 1 / 2 \mathrm{p} 90^{\mathrm{rsk}}$ & activation of cardiac & {$[28]$} \\
\hline & VEGFR2 & & $\begin{array}{l}\text { myocytes and fibroblasts in } \\
\text { response to ischemic stresses }\end{array}$ & \\
\hline & VEGFR2 & PI3K-Akt-eNOS & $\begin{array}{l}\text { endothelial cell survival } \\
\text { vascular neogenesis in the } \\
\text { myocardium }\end{array}$ & {$[29,30]$} \\
\hline & VEGFR2 & $\begin{array}{l}\text { ICPP-induced ERK } \\
\text { phosphorylation }\end{array}$ & $\begin{array}{l}\text { improvement of ischemia- } \\
\text { reperfusion-induced } \\
\text { mitochondrial dysfunction }\end{array}$ & {$[31]$} \\
\hline \multirow[t]{5}{*}{ TGF- $\beta$} & $\begin{array}{l}\text { TGF- } \beta \\
\text { RII+RI }\end{array}$ & Smad 3 & $\begin{array}{l}\text { infarct healing and cardiac } \\
\text { remodeling }\end{array}$ & [7] \\
\hline & TGF- $\beta$ & p42/p44 MAPK & relieving apoptosis of & [32] \\
\hline & $\mathrm{RII}+\mathrm{RI}$ & & $\begin{array}{l}\text { myocytes and limiting infarct } \\
\text { size }\end{array}$ & \\
\hline & TGF- $\beta$ & MAPK & protecting against myocardial & [33] \\
\hline & $\mathrm{RII}+\mathrm{RI}$ & & $\begin{array}{l}\text { ischemia-reperfusion injury } \\
\text { by attenuating inflammation } \\
\text { and cardiomyocyte apoptosis }\end{array}$ & \\
\hline $\begin{array}{l}\text { FGF1, } \\
\text { FGF2 }\end{array}$ & FGFR1 & PI3K-Akt MEK1/2-Erk 1/2 & direct cardioprotective effect & [3] \\
\hline \multirow[t]{3}{*}{ FGF2 } & FGFR1 & PI3K/Akt & protecting cardiomyocytes & {$[34]$} \\
\hline & FGFR1 & MAPK & $\begin{array}{l}\text { against oxidative stress } \\
\text { promoting cardiac }\end{array}$ & [35] \\
\hline & & & hypertrophy and fibrosis & \\
\hline FGF21 & FGFR1c & $\begin{array}{c}\text { ERK1/2-p38 MAPK- } \\
\text { AMPK }\end{array}$ & $\begin{array}{l}\text { preventing cardiomyocyte } \\
\text { apoptosis }\end{array}$ & {$[36]$} \\
\hline \multirow[t]{2}{*}{ IGF-I } & IGF-IR & PI3K/Akt & $\begin{array}{l}\text { hypertrophy and } \\
\text { proliferation of } \\
\text { cardiomyocytes }\end{array}$ & {$[37,38]$} \\
\hline & & & $\begin{array}{c}\text { adaptive right ventricular } \\
\text { hypertrophy }\end{array}$ & \\
\hline PDGF-BB & $\begin{array}{c}\text { not } \\
\text { investigated }\end{array}$ & PI3K/Akt & $\begin{array}{l}\text { promoting contractility } \\
\text { preventing apoptosis of } \\
\text { cardiomyocytes }\end{array}$ & [39] \\
\hline PDGF-BB & PDGFR- $\beta$ & ERK1/2, MEK, PLC, PKC & $\begin{array}{l}\text { promoting growth of } \\
\text { cardiomyocytes }\end{array}$ & [40] \\
\hline
\end{tabular}

Akt: protein kinase B; AMPK: AMP-activated protein kinase; eNOS: endothelial nitric oxide synthase; ERK: extracellular signal regulated kinase; FGF: fibroblast growth factor, FGFR: FGF receptor; ICPP: increasing capillary permeability protein; MEK or MAPK: mitogen-activated protein kinase, $\mathrm{p} 90^{\text {rsk }}$ - ribosomal s6 kinase; PI3K: phosphoinositide 3-kinase; PDGF: platelet-derived growth factor; PKC: protein kinase C; PLC: phospholipase C; TGF- $\beta$ : transforming growth factor beta; TGF- $\beta$ R: TGF- $\beta$ receptor; VEGF: vascular endothelial growth factor; VEGFR: VEGF receptor. 


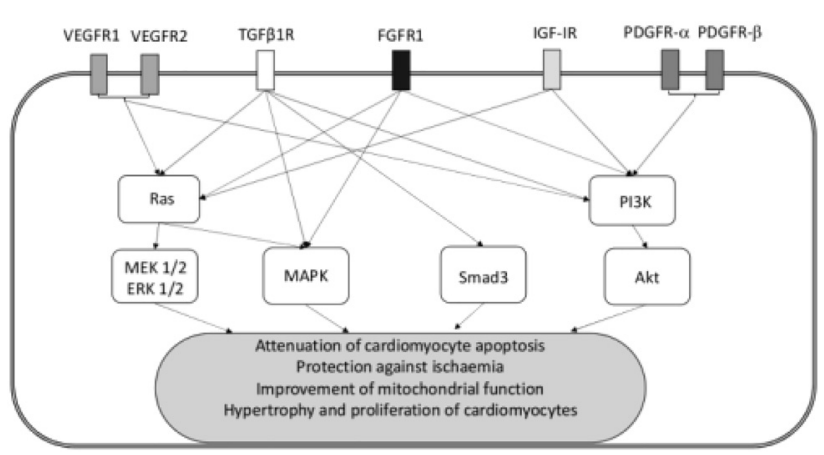

Fig. 3. Intracellular pathways of growth factors involved in myocardial protection in PAH. Growth factors use similar intracellular pathways in adaptation mechanisms of cardiomyocytes. These mechanisms support myocardial viability against ischemic and metabolic injury, might aid the development of adaptive myocardial hypertension and could lead to the preservation of the right ventricle function in early stage of PAH. VEGFR: vascular endothelial growth factor receptor; TGF $\beta 1 \mathrm{R}$ : transforming growth factor- $\beta 1$ receptor; FGFR: fibroblast growth factor receptor; IGF-IR: Insulin-like growth factor-I receptor; PDGFR: Platelet-derived growth factor receptor; Ras: intracellular signal transduction protein; MEK or MAPK: mitogen-activated protein kinase; SMAD: specific intracellular signal transduction protein; ERK: extracellular signal regulated kinase; PI3K: phosphoinositide 3-kinase; Akt: protein kinase B

in an experimental model of LV hypertrophy the overexpression of VEGF using a viral vector resulted in the preservation of cardiac function [51]. Interestingly, the plasma VEGF levels of patients did not change after 3 months of PAH-targeted therapy [49], although treatment was associated with a decrease in PVR and an improvement of cardiac index.

The association of circulating GFs level with clinical characteristics in patients with PAH are listed in Table 3.

\section{TRANSFORMING GROWTH FACTOR- $\beta$ (TGF- $\beta$ )}

TGF- $\beta$ is a pleiotropic and multifunctional polypeptide, which is a member of the TGF superfamily together with other proteins including activins and BMP. TGF- $\beta$ binds to the type II TGF- $\beta 1$ receptor, which activates the TGF- $\beta 1$ receptor type I, and the signal is transmitted by these transmembrane serine/threonine kinase receptors to activate the Smads and Smad-independent pathways, the phosphoinositide 3-kinase (PI3K)/Akt and the MEK1/2-Erk1/2 kinase cascades [3]. TGF- $\beta$ regulates many physiological processes such as embryonic development, cell growth and differentiation, immune processes and angiogenesis and it also stimulates the production of extracellular matrix components, the synthesis of elastin, and it can control the proliferation of smooth muscle cells as well [54].

An elegant human study showed that in normal human pulmonary arteries TGF- $\beta$ receptor expression is more pronounced in endothelial cells than in vascular smooth muscle cells [55]. Plexiform lesions in IPAH are associated with the loss of TGF- $\beta$ signaling, suggesting a role for this pathway in the abnormal growth of endothelial cells in patients. In contrast, a rare form of $\mathrm{PAH}$ associated with schistosomiasis showed heightened TGF- $\beta$ signaling in the pulmonary 
Table 3. Plasma growth factor concentration and its association with clinical factors in patients with PAH

\begin{tabular}{|c|c|c|c|c|}
\hline $\begin{array}{l}\text { Growth } \\
\text { factor }\end{array}$ & $\begin{array}{c}\text { Patient } \\
\text { population }\end{array}$ & Concentration & Association with clinical factors & Reference \\
\hline VEGF & $\begin{array}{c}\text { IPAH } \\
\text { primary } \mathrm{PH}\end{array}$ & $\begin{array}{c}82 / 0-345 / \mathrm{pg} / \mathrm{mL} \\
41.4(7.5-92) \mathrm{pg} / \\
\mathrm{mL}\end{array}$ & $\begin{array}{c}\text { TAPSE } \\
\text { when combined with FGF-2: } \\
\text { - mean PAP } \\
\text { - right atrial pressure } \\
\text { - WHO functional class }\end{array}$ & $\begin{array}{l}{[50]} \\
{[52]}\end{array}$ \\
\hline TGF- $\beta$ & $\begin{array}{c}\text { IPAH } \\
\text { hereditary PAH }\end{array}$ & $\begin{array}{l}5.02(3.34-8.29) \mathrm{ng} / \\
\mathrm{mL} \\
4.36(2.98-7.05) \mathrm{ng} / \\
\mathrm{mL}\end{array}$ & $\begin{array}{c}\text { - WHO functional class } \\
\text { - independent factor for all-cause } \\
\text { mortality }\end{array}$ & {$[53]$} \\
\hline FGF2 & primary $\mathrm{PH}$ & $\begin{array}{c}2.15(0.5-9.3) \mathrm{pg} / \\
\mathrm{mL}\end{array}$ & - WHO functional class & {$[52]$} \\
\hline
\end{tabular}

Data are shown as median/range/or (interquartile range). FGF: fibroblast growth factor; IPAH: idiopathic pulmonary arterial hypertension; PAH: pulmonary arterial hypertension; PAP: pulmonary arterial pressure; PH: pulmonary hypertension; TAPSE: tricuspid annular plane systolic excursion; TGF: transforming growth factor; VEGF: vascular endothelial growth factor, WHO: World Health Organization.

arteries both in patients and in infected mice [56]. Importantly, the blockade of TGF- $\beta$ signaling yielded protection against $\mathrm{PAH}$ in the animal model. Furthermore, the upregulation of pulmonary TGF- $\beta$ signaling was observed in the experimental model of monocrotaline-induced $\mathrm{PAH}$, and the blockage of TGF- $\beta$ receptor type I resulted in attenuated morphological presentation of pulmonary vascular remodeling including decreased early vascular cell apoptosis, adventitial cell proliferation and matrix metalloproteinase expression [57]. The increased expression of the growth differentiation factor-15 (GDF-15), a distant member of the TGF- $\beta$ cytokine superfamily was observed in macrophages in the lungs of patients with PAH associated with systemic sclerosis [58]. GDF-15 can exert anti-apoptotic effects on the cells of the pulmonary vasculature and contribute to vascular remodeling.

The function of TGF- $\beta$ during myocardial repair and remodeling after cardiac injury has been studied in cardiac disorders. TGF- $\beta$ pre-treatment reduced the myocardial infarct size in an animal model by decreasing the level of oxidative stress markers in the coronary circulation and preserving endothelium-dependent coronary relaxation [59]. Other studies attributed these direct cardioprotective effects of TGF- $\beta$ to intracellular signal transduction pathways including the MEK1/2Erk1/2, a component of the RISK pathway [3]. Extensive animal studies on left heart failure showed that TGF- $\beta$ overexpression promotes myocardial hypertrophy, remodeling and fibrosis (reviewed in detail [60]), suggesting an important role in myocardial adaptation, i.e. the development of ventricular hypertrophy and diastolic dysfunction. Indeed, serum TGF- $\beta$ levels correlated with left ventricular structural abnormalities in long-term hypertensive patients [61]. An excessive TGF- $\beta$ production may be harmful to myocardial function by increasing myocardial fibrosis. In support, a highly elevated plasma TGF- $\beta$ concentration was found to be an independent predictor of all-cause mortality in patients with IPAH and FPAH [53]. Nonetheless, a moderate induction of TGF- $\beta$ signaling may be necessary for cardiac adaptation during pressure overload, as this GF inhibits uncontrolled matrix degradation that could result in cardiac dilation [60]. 


\section{FIBROBLAST GROWTH FACTOR (FGF)}

Fibroblast growth factors are multifunctional polypeptides that affect cell growth and differentiation. The FGF family has 23 members, and certain mediators exert intracrine stimulus, while others have paracrine or endocrine effects. The paracrine and the endocrine members bind to tyrosine kinase receptors (FGFR 1-4), which mainly activate the intracellular signal transduction protein-mitogen-activated protein kinase (RAS-MAPK) or PI3K/Akt intracellular pathways to induce mitogenic cell response and promote cell survival [27]. In addition, FGF-2 stimulation inhibits endothelial cell apoptosis by inducing signaling via the pathways of B-cell lymphoma (BCL) 2 and BCL extra long [62]. Several members of the FGF family, including FGF-2, -16, -21 and -23 have been implied in the pathophysiological processes of cardiac diseases [35]. Among them, the effects of FGF-2 have been studied most extensively in cardiovascular pathologies.

The upregulated expressions of FGF-2 and FGF receptor 1 (FGFR-1) were demonstrated in the pulmonary arteries of animals with monocrotaline-induced PAH, and FGFR-1 blockage resulted in attenuated vascular remodeling [63]. Additionally, endothelial cells isolated from distal pulmonary arteries of patients with IPAH showed heightened FGF-2 production. Stimulation with FGF-2 resulted in increased proliferative response and survival of these cells, whereas dampened FGF-2 signaling normalized these cellular functions suggesting a role of FGF-2 in the development of an abnormal phenotype of pulmonary arterial endothelial cells [62]. Benisty et al. found that both urinary and plasma FGF-2 were significantly higher in patients with PAH than in control subjects. Interestingly, there was a difference in FGF-2 concentrations according to etiologies of $\mathrm{PH}$, with the highest levels seen in patients with primary PAH compared to patients with congenital heart disease or connective tissue disease. However, they did not find a relationship between either blood or urinary FGF-2 levels and cardiac index, suggesting that an increase in mediator concentrations was not the result of a low cardiac output state or systemic hypoperfusion [52].

FGF-2 is released from damaged myocardial cells and it is mainly stored in the extracellular matrix. It modulates vascular endothelial and smooth muscle cell growth and migration, and the synthesis of extracellular matrix proteins. Accordingly, FGF-2 can stimulate the development of ventricular hypertrophy and fibrosis during cardiac remodeling by activating the MAPK signal pathway [35]. It was demonstrated in an in vitro model that isolated adult myocytes upregulated protein synthesis and increased in size in response to co-culture with FGF-2 [64]. In line with this, FGF-2-deficient mice showed a failure in the development of cardiac hypertrophy when exposed to pressure overload to the LV [65]. Furthermore, FGF-2 overexpression led to excessive hypertrophic response to isoproterenol, which was associated with ischemic preconditioning and the increased resistance of the myocardium to ischemia-reperfusion injury [66]. Hence, FGF-2, secreted by cardiomyocytes in response to myocardial damage such as ischemia, can play a role in myocardial protection and regeneration processes [67]. Accordingly, pre-treatment with FGF-2 reduced the size of the infarcted area in the isolated rat heart [68]. Other authors demonstrated that FGF-2 given during reperfusion protected against ischemia-reperfusion injury of the ex vivo heart [69].

\section{INSULIN-LIKE GROWTH FACTOR-I (IGF-I)}

IGF-I is a polypeptide produced in the liver as a result of growth hormone stimulation, but a limited amount can also be synthetized in the target tissue including the heart. It is bound to 
IGF-binding factors in the circulation, and only a small fraction of IGF-I (approximately 1\%) can be found as a free molecule [70]. This factor exerts its biological actions by binding to the IGF-I receptor (IGF-IR), a tyrosine kinase receptor, which is expressed in multiple tissues, and upon activation it supports cell survival, stimulates cellular migration and proliferation, and suppresses autophagy via multiple intracellular cascades including PI3K/Akt, ERK, Ras/Raf/ mitogen-activated protein kinase pathways [3]. IGF-I promotes the synthesis and inhibits the breakdown of proteins in cardiomyocytes via the PI3K/Akt cascade, thereby contributing to physiological cardiac hypertrophy $[38,71]$.

IGF-I was implicated in the development of pulmonary vascular remodeling. The proliferation of PASMC was attenuated in the absence of IGF-I or after the inhibition of IGF-IR. In addition, the smooth muscle cell-specific deletion of IGF-I inhibited the development of hypoxia-induced $\mathrm{PH}$ in neonatal but not adult mice [72].

Early studies showed that IGF-I treatment attenuates hypoxia-reoxygenation injury [73] and also suppresses doxorubicin-induced apoptosis of cardiomyocytes in vitro [74]. Moreover, the cardiac gene transfer of IGF-I resulted in reduced infarct size after ischemia-reperfusion injury in vivo [75]. Of note, IGF-I transgenic mice presented with preserved left ventricular contractility in aging animals, which was associated with the improved regenerative capacity of cardiac stem cells [76]. In patients with chronic left heart failure, a single intravenous infusion of IGF-I resulted in decreased afterload (i.e. decreased systemic vascular resistance), it induced positive inotropic effects and thereby improved cardiac index. However, it did not influence PAP and PVR [77].

In the animal model of monocrotaline-induced PAH and in patients with IPAH an increased level of IGF-I was measured in the hypertrophied RV and in the explanted lungs [78,79]. The pathophysiological significance of these findings is currently unclear. In young, but not in adult mice suffering from $\mathrm{PH}$ induced by hypoxia or pressure overload, the genetic inactivation or the pharmacological blockage of IGF-IR was associated with improved right heart function [79]. Nonetheless, an increase in IGF-I expression in right ventricular cardiomyocytes was associated with the significant improvement of cellular cross-sectional area [80]. Importantly, adaptive right ventricular hypertrophy (due to hypoxia or pressure overload) was associated with the increased expression of IGF-I, which was, however, missing in a rat model of right heart failure [37].

\section{PLATELET-DERIVED GROWTH FACTOR (PDGF)}

Four polypeptide chains with a common structure have been described in the PDGF family, namely PDGF-A, PDGF-B, PDGF-C and PDGF-D. They form dimers through disulfide bonds creating the isoforms of PDGF-AA, PDGF-AB, PDGF-BB, PDGF-CC and PDGF-DD. The PDGF receptors PDGFR- $\alpha$ and PDGFR- $\beta$ are transmembrane tyrosine kinases with different affinities to these ligands. PDGF-B, PDGF-C and PDGF-D can bind to both receptor subtypes, whereas PDGF-A is restricted to PDGFR- $\alpha$. These receptors induce cellular growth during embryogenesis, carcinogenesis and also in vascular development, where they promote proliferation and survival of vascular mural cells [81].

The involvement of PDGF in vascular remodeling during the development of PAH has extensively been studied (for more details see [82]). The expression of PDGFR is upregulated and its phosphorylation is elevated in the remodeled pulmonary arterioles of patients with $\mathrm{PAH}$. These changes lead to the abnormal proliferation and migration of murine vascular smooth muscle cells, which is dependent on PI3K and phospholipase C- $\gamma$ signaling [83]. The same authors found in a 
murine model that blocked or impaired PDGF signaling was protective against the development of $\mathrm{PH}$ and right ventricular hypertrophy induced by chronic hypoxia. Others described the critical involvement of sphingosine kinase 1 (SphK1)/sphingosine 1-phosphate (S1P) in the PDGFmediated proliferation of rat PASMC, and pre-silencing of SphK1 could reverse cell proliferation [84]. It has been demonstrated that imatinib, a multi-tyrosine kinase inhibitor including PDGFR could reverse PAH in animal models (monocrotaline-induced or hypoxic PH). Furthermore, in the monocrotaline rat model imatinib therapy reversed hemodynamic changes and vascular remodeling [19]. Therefore, blocking PDGF signaling seemed a potential drug target. Although imatinib as an add-on therapy for 24 weeks might convey some clinical benefit (an increase in sixminute walking distance) as shown by a clinical trial in patients with PAH [85], a 3-year open label trial demonstrated a high burden of complications with a number of unexpected cases of subdural hematoma discouraging the use of imatinib therapy in PAH [86].

There is also evidence that the PDGF pathway can also induce cardioprotective effects in heart conditions. In a murine model of cardiac ischemia the pharmacological blockage of both PDGFR- $\alpha$ and PDGFR- $\beta$ led to defective angiogenesis and increased permeability of new vessels in the infarcted area [87]. Rat cardiomyocytes under hypoxia upregulate PDGF-BB, which promotes cell survival [88]. It was also shown in engineered heart tissue that PDGF-BB stimulation conveys an anti-apoptotic effect and promotes contractility through PI3K-Akt signaling [39]. Pre-treatment with PDGF-AB decreased infarct size after coronary occlusion in animal models, which was related to the production of VEGF by cardiac endothelial cells [89]. In a rat myocardial infarction model the sequential delivery of VEGF and PDGF resulted in improved cardiac function, ventricular wall thickness and angiogenesis, as well as better cardiac muscle survival in the infarcted zone [90]. The local administration of PDGF to the myocardium by means of nanofibers in rats led to PDGFR- $\beta$ phosphorylation and sustained improvement in cardiac function after experimental myocardial infarction [91]. Interestingly, stem cells overexpressing VEGF and PDGF migrate to the site of myocardial infarct to decrease its size, improve angiogenesis, cardiac function and exercise capacity as shown in rats [92]. Data in $\mathrm{PAH}$ are very limited; however, a decrease in serum PDGF-AA and PDGF-BB concentrations were found in IPAH compared to control subjects [93]. Future studies should give more insight into the potential beneficial effect of PDGF on cardiac function in PAH.

\section{CLINICAL OUTLOOK}

As circulating biomarkers, GFs might be reflecting cellular changes both in the pulmonary vasculature and cardiomyocytes in the RV. Therefore, they can aid the diagnosis of PH in early stages of disease in populations at high risk such as family members of patients with hereditary PAH, subjects with scleroderma or HIV. As some GFs, particularly VEGF or FGF-2 have been positively associated with right ventricular function, they might be early signals of deterioration in right heart function before overt decline can be detected by cardiac imaging. Moreover, as biomarkers of cardiac function in a composite model they might complement patient stratification to monitor and predict disease progression, which is an important clinical goal during disease management. In this way clinicians can be guided to timely escalate treatment for the long-term benefit of patients.

In spite of the limited evidence, GFs may also be drug targets as they potentially attenuate pulmonary vascular remodeling and also have beneficial effects on cardiomyocyte function and 
the RV adaptation process. However, contradictory effects of GFs, such as of FGF-2 and PDGF on vascular remodeling and cardiac function have been described. Hence, further clarification on the involvement of GFs in the development and progression of $\mathrm{PH}$ is warranted with the possibility that these pathways might be specific for certain subtypes of $\mathrm{PH}$.

Pulmonary vasodilators including endothelin receptor antagonists, phosphodiesterase-5inhibitors and prostacyclins are available during the management of PAH. The interaction of these drugs with GFs can be hypothesized as they might modulate the same intracellular signaling pathways or interfere in other ways, like in the case of TGF- $\beta$, which is involved in the regulation of endothelin expression in the pulmonary vasculature [94]. Treprostinil, a prostacyclin analog was shown to interfere with PDGF signaling, as it improved PDGF-induced remodeling parameters in PASMCs isolated from patients with PAH. Treprostinil treatment reduced TGF- $\beta$ and connective tissue GF secretion from these cells via the increased levels of cyclic adenosine monophosphate [95]. Currently available drugs do not directly target cardiomyocyte function; however, as GFs might exert such effects, a combination therapy may have a dual influence and provide better survival than pulmonary vasodilators alone.

\section{CONCLUSIONS}

The mechanisms behind the development and progression of PAH are incompletely understood, with even less knowledge on pathways regulating right ventricular dysfunction. Although the preservation of right heart function is associated with better clinical prognosis, currently no therapies specifically target and improve right ventricular function. Experimental and human studies equivocally described the involvement of GFs such as VEGF, TGF- $\beta$, FGF-2, IGF-I and PDGF in the development of PAH, but other studies (both in other cardiac disorders and in $\mathrm{PAH}$ ) suggested that these mediators can exert beneficial effects on cardiac function. Among their multiple effects, these mediators support hypoxia-induced angiogenesis, restrict hypoxemia-related cardiac injury, promote adaptive hypertrophy and inhibit apoptosis of cardiomyocytes. These observations can pave the way to explore novel therapeutic targets to preserve or predict the progression of right heart function in patients with PAH.

\section{ACKNOWLEDGMENTS}

This work was supported by the János Bolyai Research Scholarship of the Hungarian Academy of Sciences to Zsófia Lázár (under Grant No. BO/00559/16); and the Hungarian Respiratory Foundation to Györgyi Csósza (under Grant No. MPA/2019).

\section{REFERENCES}

1. Galie N, Humbert M, Vachiery JL, Gibbs S, Lang I, Torbicki A, et al. 2015 ESC/ERS Guidelines for the diagnosis and treatment of pulmonary hypertension: The joint task force for the diagnosis and treatment of pulmonary hypertension of the European Society of Cardiology (ESC) and the European Respiratory Society (ERS): Endorsed by: Association for European Paediatric and Congenital Cardiology (AEPC), International Society for Heart and Lung Transplantation (ISHLT). Eur Respir J 2015; 46: 903-75. 
2. Bogaard HJ, Abe K. Vonk Noordegraaf A, Voelkel NF. The right ventricle under pressure: cellular and molecular mechanisms of right-heart failure in pulmonary hypertension. Chest 2009; 135: 794-804.

3. Hausenloy DJ, Yellon DM. Cardioprotective growth factors. Cardiovasc Res 2009; 83: 179-94.

4. Hefti MA, Harder BA, Eppenberger HM, Schaub MC. Signaling pathways in cardiac myocyte hypertrophy. J Mol Cell Cardiol 1997; 29: 2873-92.

5. Nickel N, Jonigk D, Kempf T, Bockmeyer CL, Maegel L, Rische J, et al. GDF-15 is abundantly expressed in plexiform lesions in patients with pulmonary arterial hypertension and affects proliferation and apoptosis of pulmonary endothelial cells. Respir Res 2011; 12: 62.

6. Perros F, Montani D, Dorfmuller P, Durand-Gasselin I, Tcherakian C, Le Pavec J, et al. Platelet-derived growth factor expression and function in idiopathic pulmonary arterial hypertension. Am J Respir Crit Care Med 2008; 178: 81-8.

7. Bujak M, Ren G, Kweon HJ, Dobaczewski M, Reddy A, Taffet G, et al. Essential role of Smad3 in infarct healing and in the pathogenesis of cardiac remodeling. Circulation 2007; 116: 2127-38.

8. Freund-Michel V, Cardoso Dos Santos M, Guignabert C, Montani D, Phan C, Coste F, et al. Role of nerve growth factor in development and persistence of experimental pulmonary hypertension. Am J Respir Crit Care Med 2015; 192: 342-55.

9. Selimovic N, Bergh CH, Andersson B, Sakiniene E, Carlsten H, Rundqvist B. Growth factors and interleukin-6 across the lung circulation in pulmonary hypertension. Eur Respir J 2009; 34: 662-8.

10. Machado RD, Eickelberg O, Elliott CG, Geraci MW, Hanaoka M, Loyd JE, et al. Genetics and genomics of pulmonary arterial hypertension. J Am Coll Cardiol 2009; 54: S32-42.

11. Orriols M, Gomez-Puerto MC, Ten Dijke P. BMP type II receptor as a therapeutic target in pulmonary arterial hypertension. Cell Mol Life Sci 2017; 74: 2979-95.

12. Morrell NW. Pulmonary hypertension due to BMPR2 mutation: a new paradigm for tissue remodeling?. Proc Am Thorac Soc 2006; 3: 680-6.

13. Kumar R, Mickael C, Kassa B, Gebreab L, Robinson JC, Koyanagi DE, et al. TGF-beta activation by bone marrow-derived thrombospondin-1 causes Schistosoma- and hypoxia-induced pulmonary hypertension. Nat Commun 2017; 8: 15494.

14. Calvani M, Rapisarda A, Uranchimeg B, Shoemaker RH, Melillo G. Hypoxic induction of an HIF-1alphadependent bFGF autocrine loop drives angiogenesis in human endothelial cells. Blood 2006; 107: 2705-12.

15. Forsythe JA, Jiang BH, Iyer NV, Agani F, Leung SW, Koos RD, et al. Activation of vascular endothelial growth factor gene transcription by hypoxia-inducible factor 1. Mol Cell Biol 1996; 16: 4604-13.

16. Yu X, Chen X, Zheng XD, Zhang J, Zhao X, Liu Y, et al. Growth differentiation factor 11 promotes abnormal proliferation and angiogenesis of pulmonary artery endothelial cells. Hypertension 2018; 71: 729-41.

17. Mattei D, Feola M, Orzan F, Mordini N, Rapezzi D, Gallamini A. Reversible dasatinib-induced pulmonary arterial hypertension and right ventricle failure in a previously allografted CML patient. Bone Marrow Transplant 2009; 43: 967-8.

18. Rasheed W, Flaim B, Seymour JF. Reversible severe pulmonary hypertension secondary to dasatinib in a patient with chronic myeloid leukemia. Leuk Res 2009; 33: 861-4.

19. Schermuly RT, Dony E, Ghofrani HA, Pullamsetti S, Savai R, Roth M, et al. Reversal of experimental pulmonary hypertension by PDGF inhibition. J Clin Invest 2005; 115: 2811-21.

20. Chin KM, Kim NH, Rubin LJ. The right ventricle in pulmonary hypertension. Coron Artery Dis 2005; 16: 13-8.

21. Reesink HJ, Marcus JT, Tulevski II, Jamieson S, Kloek JJ, Vonk Noordegraaf A, et al. Reverse right ventricular remodeling after pulmonary endarterectomy in patients with chronic thromboembolic pulmonary hypertension: utility of magnetic resonance imaging to demonstrate restoration of the right ventricle. J Thorac Cardiovasc Surg 2007; 133: 58-64. 
22. Handoko ML, de Man FS, Allaart CP, Paulus WJ, Westerhof N, Vonk-Noordegraaf A. Perspectives on novel therapeutic strategies for right heart failure in pulmonary arterial hypertension: lessons from the left heart. Eur Respir Rev 2010; 19: 72-82.

23. Galie N, Manes A, Palazzini M, Negro L, Romanazzi S, Branzi A. Pharmacological impact on right ventricular remodelling in pulmonary arterial hypertension. Eur Heart J 2007; 9: H68-74.

24. Vonk Noordegraaf A, Galie N. The role of the right ventricle in pulmonary arterial hypertension. Eur Respir Rev 2011; 20: 243-53.

25. Ghio S, Pazzano AS, Klersy C, Scelsi L, Raineri C, Camporotondo R, et al. Clinical and prognostic relevance of echocardiographic evaluation of right ventricular geometry in patients with idiopathic pulmonary arterial hypertension. Am J Cardiol 2011; 107: 628-32.

26. Badagliacca R, Papa S, Poscia R, Pezzuto B, Manzi G, Torre R, et al. The importance of right ventricular function in patients with pulmonary arterial hypertension. Expert Rev Respir Med 2018; 12: 809-15.

27. Goetz R, Mohammadi M. Exploring mechanisms of FGF signalling through the lens of structural biology. Nat Rev Mol Cell Biol 2013; 14: 166-80.

28. Seko Y, Takahashi N, Tobe K, Ueki K, Kadowaki T, Yazaki Y. Vascular endothelial growth factor (VEGF) activates Raf-1, mitogen-activated protein (MAP) kinases, and S6 kinase (p90rsk) in cultured rat cardiac myocytes. J Cell Physiol 1998; 175: 239-46.

29. Gerber HP, McMurtrey A, Kowalski J, Yan M, Keyt BA, Dixit V, et al. Vascular endothelial growth factor regulates endothelial cell survival through the phosphatidylinositol 3'-kinase/Akt signal transduction pathway. Requirement for Flk-1/KDR activation. J Biol Chem 1998; 273: 30336-43.

30. Partovian C, Adnot S, Eddahibi S, Teiger E, Levame M, Dreyfus P, et al. Heart and lung VEGF mRNA expression in rats with monocrotaline- or hypoxia-induced pulmonary hypertension. Am J Physiol 1998; 275: H1948-56.

31. Messadi E, Aloui Z, Belaidi E, Vincent MP, Couture-Lepetit E, Waeckel L, et al. Cardioprotective effect of VEGF and venom VEGF-like protein in acute myocardial ischemia in mice: effect on mitochondrial function. J Cardiovasc Pharmacol 2014; 63: 274-81.

32. Baxter GF, Mocanu MM, Brar BK, Latchman DS, Yellon DM. Cardioprotective effects of transforming growth factor-beta1 during early reoxygenation or reperfusion are mediated by p42/p44 MAPK. J Cardiovasc Pharmacol 2001; 38: 930-9.

33. Suchal K, Malik S, Gamad N, Malhotra RK, Goyal SN, Ojha S, et al. Mangiferin protect myocardial insults through modulation of MAPK/TGF-beta pathways. Eur J Pharmacol 2016; 776: 34-43.

34. Liu MH, Li GH, Peng LJ, Qu SL, Zhang Y, Peng J, et al. PI3K/Akt/FoxO3a signaling mediates cardioprotection of FGF-2 against hydrogen peroxide-induced apoptosis in H9c2 cells. Mol Cell Biochem 2016; 414: 57-66.

35. Itoh N, Ohta H. Pathophysiological roles of FGF signaling in the heart. Front Physiol 2013; 4: 247.

36. Zhang C, Huang Z, Gu J, Yan X, Lu X, Zhou S, et al. Fibroblast growth factor 21 protects the heart from apoptosis in a diabetic mouse model via extracellular signal-regulated kinase 1/2-dependent signalling pathway. Diabetologia 2015; 58: 1937-48.

37. Drake JI, Bogaard HJ, Mizuno S, Clifton B, Xie B, Gao Y, et al. Molecular signature of a right heart failure program in chronic severe pulmonary hypertension. Am J Respir Cell Mol Biol 2011; 45: 1239-47.

38. McMullen JR, Shioi T, Zhang L, Tarnavski O, Sherwood MC, Kang PM, et al. Phosphoinositide 3-kinase(p110alpha) plays a critical role for the induction of physiological, but not pathological, cardiac hypertrophy. Proc Natl Acad Sci U. S. A 2003; 100: 12355-60.

39. Vantler M, Karikkineth BC, Naito H, Tiburcy M, Didie M, Nose M, et al. PDGF-BB protects cardiomyocytes from apoptosis and improves contractile function of engineered heart tissue. J Mol Cell Cardiol 2010; 48: 1316-23. 
40. Liu J, Wu LL, Li L, Zhang L, Song ZE. Growth-promoting effect of platelet-derived growth factor on rat cardiac myocytes. Regul Pept 2005; 127: 11-8.

41. Veikkola T, Alitalo K. VEGFs, receptors and angiogenesis. Semin Cancer Biol 1999; 9: 211-20.

42. Hirose S, Hosoda Y, Furuya S, Otsuki T, Ikeda E. Expression of vascular endothelial growth factor and its receptors correlates closely with formation of the plexiform lesion in human pulmonary hypertension. Pathol Int 2000; 50: 472-9.

43. Louzier V, Raffestin B, Leroux A, Branellec D, Caillaud JM, Levame M, et al. Role of VEGF-B in the lung during development of chronic hypoxic pulmonary hypertension. Am J Physiol Lung Cell Mol Physiol 2003; 284: L926-37.

44. Partovian C, Adnot S, Raffestin B, Louzier V, Levame M, Mavier IM, et al. Adenovirus-mediated lung vascular endothelial growth factor overexpression protects against hypoxic pulmonary hypertension in rats. Am J Respir Cell Mol Biol 2000; 23: 762-71.

45. Taraseviciene-Stewart L, Kasahara Y, Alger L, Hirth P, Mc Mahon G, Waltenberger J, et al. Inhibition of the VEGF receptor 2 combined with chronic hypoxia causes cell death-dependent pulmonary endothelial cell proliferation and severe pulmonary hypertension. FASEB J 2001; 15: 427-38.

46. Levy AP, Levy NS, Loscalzo J, Calderone A, Takahashi N, Yeo KT, et al. Regulation of vascular endothelial growth factor in cardiac myocytes. Circ Res 1995; 76: 758-66.

47. Takahashi N, Seko Y, Noiri E, Tobe K, Kadowaki T, Sabe H, et al. Vascular endothelial growth factor induces activation and subcellular translocation of focal adhesion kinase (p125FAK) in cultured rat cardiac myocytes. Circ Res 1999; 84: 1194-202.

48. Luo Z, Diaco M, Murohara T, Ferrara N, Isner JM, Symes JF. Vascular endothelial growth factor attenuates myocardial ischemia-reperfusion injury. Ann Thorac Surg 1997; 64: 993-8.

49. Kumpers P, Nickel N, Lukasz A, Golpon H, Westerkamp V, Olsson KM, et al. Circulating angiopoietins in idiopathic pulmonary arterial hypertension. Eur Heart J 2010; 31: 2291-300.

50. Pako J, Bikov A, Karlocai K, Csosza G, Kunos L, Losonczy G, et al. Plasma VEGF levels and their relation to right ventricular function in pulmonary hypertension. Clin Exp Hypertens 2015; 37: 340-4.

51. Bajgelman MC, Dos Santos L, Silva GJJ, Nakamuta J, Sirvente RA, Chaves M, et al. Preservation of cardiac function in left ventricle cardiac hypertrophy using an AAV vector which provides VEGF-A expression in response to p53. Virology 2015; 476: 106-14.

52. Benisty JI, McLaughlin VV, Landzberg MJ, Rich JD, Newburger JW, Rich S, et al. Elevated basic fibroblast growth factor levels in patients with pulmonary arterial hypertension. Chest 2004; 126: 1255-61.

53. Yan Y, Wang XJ, Li SQ, Yang SH, Lv ZC, Wang LT, et al. Elevated levels of plasma transforming growth factor-beta1 in idiopathic and heritable pulmonary arterial hypertension. Int J Cardiol 2016; 222: 368-74.

54. Huang SS, Huang JS. TGF-beta control of cell proliferation. J Cell Biochem 2005; 96: 447-62.

55. Richter A, Yeager ME, Zaiman A, Cool CD, Voelkel NF, Tuder RM. Impaired transforming growth factorbeta signaling in idiopathic pulmonary arterial hypertension. Am J Respir Crit Care Med 2004; 170: 1340-8.

56. Graham BB, Chabon J, Gebreab L, Poole J, Debella E, Davis L, et al. Transforming growth factor-beta signaling promotes pulmonary hypertension caused by Schistosoma mansoni. Circulation 2013; 128: 1354-64.

57. Zaiman AL, Podowski M, Medicherla S, Gordy K, Xu F, Zhen L, et al. Role of the TGF-beta/Alk5 signaling pathway in monocrotaline-induced pulmonary hypertension. Am J Respir Crit Care Med 2008; 177: 896-905.

58. Meadows CA, Risbano MG, Zhang L, Geraci MW, Tuder RM, Collier DH, et al. Increased expression of growth differentiation factor-15 in systemic sclerosis-associated pulmonary arterial hypertension. Chest 2011; 139: 994-1002. 
59. Lefer AM, Tsao P, Aoki N, Palladino MA, Jr. Mediation of cardioprotection by transforming growth factorbeta. Science 1990; 249: 61-4.

60. Dobaczewski M, Chen W, Frangogiannis NG. Transforming growth factor (TGF)-beta signaling in cardiac remodeling. J Mol Cell Cardiol 2011; 51: 600-6.

61. Almendral JL, Shick V, Rosendorff C, Atlas SA. Association between transforming growth factor-beta(1) and left ventricular mass and diameter in hypertensive patients. J Am Soc Hypertens 2010; 4: 135-41.

62. Tu L, Dewachter L, Gore B, Fadel E, Dartevelle P, Simonneau G, et al. Autocrine fibroblast growth factor-2 signaling contributes to altered endothelial phenotype in pulmonary hypertension. Am J Respir Cell Mol Biol 2011; 45: 311-22.

63. Zheng Y, Ma H, Hu E, Huang Z, Cheng X, Xiong C. Inhibition of FGFR signaling with PD173074 ameliorates monocrotaline-induced pulmonary arterial hypertension and rescues BMPR-II expression. J Cardiovasc Pharmacol 2015; 66: 504-14.

64. Kaye D, Pimental D, Prasad S, Maki T, Berger HJ, McNeil PL, et al. Role of transiently altered sarcolemmal membrane permeability and basic fibroblast growth factor release in the hypertrophic response of adult rat ventricular myocytes to increased mechanical activity in vitro. J Clin Invest 1996; 97: 281-91.

65. Schultz JE, Witt SA, Nieman ML, Reiser PJ, Engle SJ, Zhou M, et al. Fibroblast growth factor-2 mediates pressure-induced hypertrophic response. J Clin Invest 1999; 104: 709-19.

66. Sheikh F, Sontag DP, Fandrich RR, Kardami E, Cattini PA. Overexpression of FGF-2 increases cardiac myocyte viability after injury in isolated mouse hearts. Am J Physiol Heart Circ Physiol 2001; 280: H1039-50.

67. Kardami E, Detillieux K, Ma X, Jiang Z, Santiago JJ, Jimenez SK, et al. Fibroblast growth factor-2 and cardioprotection. Heart Fail Rev 2007; 12: 267-77.

68. Padua RR, Sethi R, Dhalla NS, Kardami E. Basic fibroblast growth factor is cardioprotective in ischemiareperfusion injury. Mol Cell Biochem 1995; 143: 129-35.

69. Jiang ZS, Padua RR, Ju H, Doble BW, Jin Y, Hao J, et al. Acute protection of ischemic heart by FGF-2: involvement of FGF-2 receptors and protein kinase C. Am J Physiol Heart Circ Physiol 2002; 282: H1071-80.

70. Lee WS, Kim J. Insulin-like growth factor-1 signaling in cardiac aging. Biochim Biophys Acta Mol Basis Dis 2018; 1864: 1931-8.

71. Fruman DA, Meyers RE, Cantley LC. Phosphoinositide kinases. Annu Rev Biochem 1998; 67: $481-507$.

72. Sun M, Ramchandran R, Chen J, Yang Q, Raj JU. Smooth muscle insulin-like growth factor-1 mediates hypoxia-induced pulmonary hypertension in neonatal mice. Am J Respir Cell Mol Biol 2016; 55: 779-91.

73. Pi Y, Goldenthal MJ, Marin-Garcia J. Mitochondrial involvement in IGF-1 induced protection of cardiomyocytes against hypoxia/reoxygenation injury. Mol Cell Biochem 2007; 301: 181-9.

74. Wang L, Ma W, Markovich R, Chen JW, Wang PH. Regulation of cardiomyocyte apoptotic signaling by insulin-like growth factor I. Circ Res 1998; 83: 516-22.

75. Chao W, Matsui T, Novikov MS, Tao J, Li L, Liu H, et al. Strategic advantages of insulin-like growth factor-I expression for cardioprotection. J Gene Med 2003; 5: 277-86.

76. Torella D, Rota M, Nurzynska D, Musso E, Monsen A, Shiraishi I, et al. Cardiac stem cell and myocyte aging, heart failure, and insulin-like growth factor-1 overexpression. Circ Res 2004; 94: 514-24.

77. Donath MY, Sutsch G, Yan XW, Piva B, Brunner HP, Glatz Y, et al. Acute cardiovascular effects of insulinlike growth factor I in patients with chronic heart failure. J Clin Endocrinol Metab 1998; 83: 3177-83.

78. Connolly M, Garfield BE, Crosby A, Morrell NW, Wort SJ, Kemp PR. miR-322-5p targets IGF-1 and is suppressed in the heart of rats with pulmonary hypertension. FEBS Open Bio 2018; 8: 339-48.

79. Shi L, Kojonazarov B, Elgheznawy A, Popp R, Dahal BK, Bohm M, et al. miR-223-IGF-IR signalling in hypoxiaand load-induced right-ventricular failure: a novel therapeutic approach. Cardiovasc Res 2016; 111: 184-93. 
80. Peters EL, Offringa C, Kos D, Van der Laarse WJ, Jaspers RT. Regulation of myoglobin in hypertrophied rat cardiomyocytes in experimental pulmonary hypertension. Pflugers Arch 2016; 468: 1697-707.

81. Medamana J, Clark RA, Butler J. Platelet-derived growth factor in heart failure. In: Barrett JE, editor. Handbook of experimental pharmacology. Switzerland: Springer Nature; 2016. 355-69 p.

82. Hu W, Huang Y. Targeting the platelet-derived growth factor signalling in cardiovascular disease. Clin Exp Pharmacol Physiol 2015; 42: 1221-4.

83. Ten Freyhaus H, Berghausen EM, Janssen W, Leuchs M, Zierden M, Murmann K, et al. Genetic ablation of PDGF-dependent signaling pathways abolishes vascular remodeling and experimental pulmonary hypertension. Arterioscler Thromb Vasc Biol 2015; 35: 1236-45.

84. Li F, Wang J, Zhu Y, Liu L, Feng W, Shi W, et al. SphK1/S1P mediates PDGF-induced pulmonary arterial smooth muscle cell proliferation via miR-21/BMPRII/Id1 signaling pathway. Cell Physiol Biochem 2018; 51: 487-500.

85. Shah AM, Campbell P, Rocha GQ, Peacock A, Barst RJ, Quinn D, et al. Effect of imatinib as add-on therapy on echocardiographic measures of right ventricular function in patients with significant pulmonary arterial hypertension. Eur Heart J 2015; 36: 623-32.

86. Frost AE, Barst RJ, Hoeper MM, Chang HJ, Frantz RP, Fukumoto Y, et al. Long-term safety and efficacy of imatinib in pulmonary arterial hypertension. J Heart Lung Transplant 2015; 34: 1366-75.

87. Zymek P, Bujak M, Chatila K, Cieslak A, Thakker G, Entman ML, et al. The role of platelet-derived growth factor signaling in healing myocardial infarcts. J Am Coll Cardiol 2006; 48: 2315-23.

88. Rong R, Wang YC, Hu LQ, He QQ, Zhou XF, Wang TH, et al. Role of endogenous PDGF-BB in cultured cardiomyocytes exposed to hypoxia. Neuropeptides 2015; 50: 43-9.

89. Xaymardan M, Zheng J, Duignan I, Chin A, Holm JM, Ballard VL, et al. Senescent impairment in synergistic cytokine pathways that provide rapid cardioprotection in the rat heart. J Exp Med 2004; 199: 797-804.

90. Awada HK, Johnson NR, Wang Y. Sequential delivery of angiogenic growth factors improves revascularization and heart function after myocardial infarction. J Control Release 2015; 207: 7-17.

91. Hsieh PC, MacGillivray C, Gannon J, Cruz FU, Lee RT. Local controlled intramyocardial delivery of plateletderived growth factor improves postinfarction ventricular function without pulmonary toxicity. Circulation 2006; 114: 637-44.

92. Das H, George JC, Joseph M, Das M, Abdulhameed N, Blitz A, et al. Stem cell therapy with overexpressed VEGF and PDGF genes improves cardiac function in a rat infarct model. PLoS One 2009; 4: e7325.

93. Lapa M, Acencio MM, Farias AQ, Teixeira LR, Fernandes CJ, Jardim CP, et al. Selectins and platelet-derived growth factor (PDGF) in schistosomiasis-associated pulmonary hypertension. Lung 2014; 192: 981-6.

94. Dhaun N, Webb DJ. Endothelins in cardiovascular biology and therapeutics. Nat Rev Cardiol 2019; 16: 491-502.

95. Lambers C, Kornauth C, Oberndorfer F, Boehm PM, Tamm M, Klepetko W, et al. Mechanism of antiremodelling action of treprostinil in human pulmonary arterial smooth muscle cells. PLoS One 2018; 13: e0205195.

Open Access Statement. This is an open-access article distributed under the terms of the Creative Commons AttributionNonCommercial 4.0 International License (https://creativecommons.org/licenses/by-nc/4.0/), which permits unrestricted use, distribution, and reproduction in any medium for non-commercial purposes, provided the original author and source are credited, a link to the CC License is provided, and changes - if any - are indicated. (SID_1) 